\title{
An exploitation plan of tidal power in the Severn Estuary
}

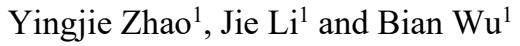 \\ ${ }^{1}$ Zhejiang Design Institute of Water Conservancy \& Hydro-Electric, Hangzhou 310051, Zhejiang Province, China
}

\begin{abstract}
The Severn Estuary has the second largest tidal range in the world and full of potential tidal power. The estuary area has great ecological value due to its nature conservation sites, biological habitats and unique coastal ecological system. Various kinds of plans and projects about exploiting the Severn Estuary have been proposed by many organizations for years. Giving the consideration of electricity generating efficiency, financial costs and especially environmental impacts, it is reasonable to believe that the application of a tidal lagoon system in the estuary area is the most suitable choice among all the options, which has the features of eco-friendly, effective, predictable and flood defending. The implementation of the Severn Estuary tidal lagoon system can be a long-term and stable renewable energy source for UK and will provide reference value for the development of other coastal area.
\end{abstract}

\section{Introduction}

The UK government has not decided the development plan of the Severn Estuary yet, despite many organizations have already proposed their ideas and projects. However, with the growing electricity demand and climate changing, the need of developing this estuary area with large tidal potential is increasing too. This dissertation will give a brief introduction of the ecological status and assets of the Severn Estuary, and then emphasis on the tidal lagoon developing plan by analyzing its advantage and feasibility, and discussing its implementation possibility.

\section{Ecology of the Severn Estuary}

The Severn Estuary is the estuary of the longest and the oddest river in UK, River Severn. It is located on the south west coast of UK between Wales and England with a funnel shape. It is a unique estuary because of its 13 metres tidal range, which is the second largest in the world. The Severn Bore is the largest bore in Europe with a flowing speed over 10 knots and duration of 2 hours, thus full of potential tidal power. Besides River Severn, three other major rivers of UK, Wye, Usk and Avon, and some other small rivers also connected to the estuary[1].

\subsection{Ecological importance}

The Severn Estuary area is considered of great importance on its ecological value, and has various nature conservation sites.

The estuary itself is designated as a Ramsar Site, a Special Area of Conservation and a Special Protection
Area[2]. Special Areas of Conservation and Special Protection Areas are also known as European Marine Sites, which can be designated based on the legislation of European Wild Birds and Habitats Conservation Directive Community. Ramsar Sites are decided by the Convention on Wetlands of International Importance, which are international recognized and should be treated as same as European Marine Sites based on UK government policy[3].

The SSSIs, Sites of Special Scientific Interest are designated by Natural England and the Countryside Council for Wales. The Severn Estuary contains Upper Severn Estuary SSSI, the Taf/Ely Estuary SSSI and Bridgwater Bay National Nature Reserve, Steep Holm and Flat Holm[4]. These SSSIs are of great importance for wintering and wading birds, they are the major parts of large area habitats. Steep Holm is a small island on the west of Brean Down in the Bristol Channel. The island has 260 recorded vegetation species including some rare ones and is being used as a staging post by migrant birds. It also provides the opportunity for field study of genetically isolated species of plants and animals[4]. Flat Holm is located in the south east of the Severn Estuary off the Welsh coast. The island has some rare coastal plant species. It is one of the few places where the rare wild leek and the bird's-foot clover can be found in Britain. It is also a notable breeding colony for various kinds of gulls and more than 100 pairs of Shelduck[5].

The landscape and topography of the Severn Estuary is archaeologically rich and varied. The coastal land area of River Severn not only contains huge potential value for archaeological researching, but also has a rich nautical heritage including archaeological record of coastal industries, transportation routes, and the way of people once living in this area. The archaeological 
resources in the estuary area are now being threatened by both natural processes and pressure from human infrastructure construction activities along the shoreline.

There are also several Scheduled Ancient Monuments in the estuary area. Developments proceed in SAM areas need to have planning permission, mitigation strategies making and archaeological impact assessment at the early stage of planning process. The project proposer should also prepare appropriate actions when unexpected remains are uncovered[6].

\subsection{Ecological Assets}

The Severn Estuary area has various significant estuarine and intertidal habitats, with amount of unique wild animal species, including waterfowl, migratory fish and invertebrates.

The Severn Estuary is an important link spot for migratory wildfowl and waders moving form Siberia to Africa. It can be used as a wintering ground or a re-fuelling station on the way to or back from wintering ground by migratory birds[7]. The annual average of total wintering waders and wildfowl is around 65000 individuals, which makes the Severn Estuary ranking in the top 20 waterfowl assemblage sites in the world[7]. The main internationally important bird species including bewick's swan, European white fronted goose, shelduck, redshank and dunlin. The number of European white fronted goose in the Severn Estuary area is the largest in UK.

The Severn Estuary is also a greatly crucial area for migratory fish. They will pass through the estuary from the ocean to freshwater such as River Usk or Wye to spawn, and return back to the sea until certain ages. These fish species including salmon, sea trout, river and sea lamprey and twaite and allis shad. Among these, shads and lamprey are included in the Habitats Directive, which means they need higher level of protection[8]. Another major feature of the estuary is the migration of eels. Eel larvae will drift following the ocean flow from their birthplace, Sargasso Sea across the Atlantic Ocean to the Severn Estuary. After an eight to fifteen years period of growing in the Severn River upstream, the mature eel will go back to the Sargasso Sea through the Severn Estuary for breeding[9].

The various landforms in the Severn Estuary ensured its habitats diversity, comprising intertidal mudflats and sandflats, sandbanks, sabellaria reefs, saltmarsh, shingle and rocky shore, coastal grazing marsh and ditches. Among these, the saltmarshes generated by the huge tidal range are particularly important as migratory bird habitat, and its rare terraced shape also makes it a highly unusual morphology which helps maintain the range and variation of saltmarshes in UK[10].

Other wild species such as abundant shrimps, otters and rats also living in the Severn Estuary, together with birds and fishes formed a coastal ecological system.

\section{Ecologically sustainable tidal power development plan}

Due to the rapidly growing energy demand, and the goal of producing renewable sources and reducing carbon emission, the proposal of using the great tidal power of the Severn Estuary in southwest Britain, which can possibly generate $5 \%$ of the UK's total energy, has been reconsidered.

Giving the consideration of electricity generating efficiency, financial costs and especially environmental impacts, the application of tidal lagoon system is the most reasonable and practical choice among all the options.

\subsection{Lagoon Mechanism}

Tidal lagoon is a man made rock enclosure impoundment in the tidal area. It will shape like an oval wall surround a shallow coastal sea, so it will not fully enclosing the whole Severn Estuary. The main function of a tidal lagoon is basically separating a certain part of the tidal water away from the natural flow both in the time of high tide and ebb. When ebbing, the water inside the lagoon will be trapped and gradually cause a water level difference against natural sea level. When the level difference is big enough, the sluice gates built on the wall will open and allow the trapped water to release. The rushing water will push the installed underwater hydroelectric turbines to rotate and thus generating electricity. The same process will happen when tide rising because the device works in both directions, water will be kept out of the lagoon until certain water level difference. Then the sluices open and the hydroelectric turbines will start rotating and generating electricity again[11]. The main part of the lagoon wall will be built from large amount of stone, rubble and concrete, and the outer surface can be covered by grass or plants to provide habitats for animals. A design of moderate pumping can be used in a lagoon project to promote the power output by fully utilizing its spare capacity. Based on the predictable tide flow and uneven time distribution of electricity demand, an appropriate plan of pumping, storing and dispatching can greatly enhance the working efficiency of the lagoon system[12].

\subsection{Tidal Lagoons in the Severn Estuary}

There is more than one location suitable for a tidal lagoon in the Severn Estuary and the ultimate goal of lagoon developers is to set up a multi-lagoons system.

The Swansea Bay lagoon is the first step of the whole plan. After consulted with more than 100 statutory consultees and thousand of local people, the developers have already submitted the plan of tidal lagoon in Swansea Bay to the UK government in 2014, the project will probably cost 850 million GBP. $86 \%$ of the local community support the construction of lagoon and are willing to invest in this project.

According to the plan, the whole rock wall will be six miles long, start form Swansea Docks to the New Fabian Way campus near Swansea University forming a U shape enclosure. The impounding water area is about 11 square $\mathrm{kms}(4$ square miles) and the lagoon wall will be 5 to 20 
meters high various according to the height of underwater seabed reef[13]. The construction time will be around two years and can offer more than 1800 jobs. At the end of the lagoon's rock wall, the developers also plan to build an offshore visitor centre and various water sports facilities with access by footpath and bus for the purpose of introducing local sea culture and visitors' education and entertainment. The lagoon will be working 14 hours a day and the predicted renewable electricity generated by it will be about $0.42 \mathrm{TWh}$ annually. Its design life is 120 years, which means its output can support over 120,000 homes in UK for 120 years[13].

The technology of tidal lagoon is already mechanically mature. The Swansea Bay Lagoon could be the first proof of the lagoon concept and leading a new manufacturing direction. The intention of the lagoon developers is to meet $10 \%$ of the UK's electricity demand from the tidal power by building at least five tidal lagoons by the year of 2023[13]. According to the actual condition, there are suitable sites and enough space for up to three huge lagoons in the whole Severn Estuary area. The most possible and practical site plans for further lagoon construction are the Bridgewater Bay lagoon and the Cardiff-Newport lagoon, both have been contained in the five considerable schemes shortlist announced by the government in 2009. The Bridgewater Bay lagoon will be located on the English side of the estuary from Hinkley Point to Weston super Mare, and the Cardiff-Newport lagoon will stretch from Cardiff Bay to Newport in Wales. These two projects are much larger scale than the Swansea Bay lagoon, the water area they impound will be 91 and 72 square kms respectively, and consequently will generate 9.1TWh and 7.4TWh renewable electricity power annually[14].

Due to the large scale, the financial cost of both projects will be around 3 billion GBP. However, the project details and implementation feasibilities still need further assessments, and also depending on the actual working efficiency of the Swansea Bay lagoon.

\subsection{Advantages of Tidal Lagoon}

\subsubsection{Eco-friendly}

The most attractive and obvious advantage of implementing tidal lagoons in the Severn Estuary area is the less environmental and ecological damaging than its main competitor Severn Barrage and other options. The lagoon will not entirely block the estuary like a barrage or a tidal fence, it just impound a certain offshore area and will leave enough water space for shipping or salmon passing through. The conservation of rich inter-tidal area is another concern from the environmentalists. The coastal-facing lagoon-walls will be built around the low water mark, no more than one mile from the coast, basically avoid the inter-tidal area. Bridgewater Bay, one of the further lagoon sites, is entirely outside the inter-tidal area, in fact according to a report commissioned by a study group in 2004, a lagoon construction in Bridgewater Bay can somehow help reducing the salt erosion problems thus protect the shoreline[15]. In terms of bird habitats, the lagoon walls covered with plants can be treated as isolated island, which might somehow provide additional staging post for migratory birds. Unlike the Severn Barrage, all the expected lagoon sites in this area are relatively far from the Steep Holm and Flat Holm, which means the lagoon plan will minimize negative impacts to environmental sensitive areas[4].

\subsubsection{Effective}

The electricity generating efficiency of tidal lagoon is much higher than that of tidal barrage. The power output per mile square impounded area of a lagoon is almost twice as much than a barrage[16]. A high working efficiency means a better and more reasonable use of the tidal resource and its financial cost.

\subsubsection{Predictable}

The output capability of tidal lagoon is highly predictable because the natural tide pattern is predictable. Such predictable tidal power transformed and dispatched by tidal lagoons with certain pumping and storing capacities will also fix the unpredictable problems of existing power generating technologies, and make contribution to the integration of intermittent renewable energy like wind and solar power.

\subsubsection{Flood Defending}

The North-Wales coast and Somerset Levels have both been plagued by massive problems of flooding for a long time. However, water engineering experts believe that the constructing of Swansea Bay lagoon and Bridgewater Bay lagoon can also play an important role in flood defending. With the existence of lagoons, the government will be able to control the water level in it to protect the vulnerable coastal area from extreme flooding, storm surge and any other wave actions[15].

\section{Comparison and implementation plan}

Based on the principle of sustainable development, we cannot just focus on the amount of generated power and commercial profits, but also should concern the irreversible damage might caused by the proposed plans. Including tidal lagoon, there are several possible development plans for the estuary area until now and each of them has obvious flaws. The Severn Barrage will cause large scale of habitats losing and impact fish migratory, the construction of tidal lagoons need large number of aggregates, and both tidal fence and tidal reef are still in a stage of immature technology and have amounts of uncertainties. However, after considering all impact terms, it is reasonable to believe that tidal lagoon is the best exploitation plan among all the options.

The most practical and reasonable plan currently is to build the Swansea Bay lagoon first and evaluate on its working efficiency and relevant environmental impacts 
since it is a relatively small scale project. Then decision maker can decide on whether and how to set up other tidal lagoons in the whole Severn Estuary area.

\section{Conclusion}

In summary, the Severn Estuary has the most significant tidal resource in UK, and will be the main development target site of renewable power generation. The protection of ecological environment should play an important role in the development plan decision making process because the estuary's great ecological value and various nature conservation sites. The application of a tidal lagoon system in the estuary area is considered to be the most suitable choice. Although the amount of electricity generated by tidal lagoon project might be just half of the Severn Barrage, its other features like highly effective, flood defending and particularly eco-friendly are more important and suitable for the Severn Estuary. Further more, the implementation of tidal lagoon plan will provide significant reference value for the development of lagoons in other coastal area such as Colwyn Bay and Liverpool Bay. With the UK's long coastline, the whole country will have huge potential to develop more lagoon projects, along with wind, solar power and other forms of renewable energy to create a low carbon future.

\section{Reference}

1. G.E. Petts, RIVER RES APPL, 2(3), 201-220(1988)

2. S.D. Edwards, P.J.S. Jones, D.E. Nowella, OCEAN COAST MANAGE, 36(1-3), 143-165(1997)

3. C.M. Finlayson, N.C. Davidson, A.G. Spiers, N.J. Stevenson, MAR FRESHWATER RES, 50(8), 717-727(1999)

4. N.H.K. Burton, A.J. Musgrove, M.M. Rehfisch, N.A. Clark, MAR POLLUT BULL, 61(1-3), 115-123(2010)

5. T.H. Harrtsson, H.G. Hurrell, ZOOLOGY, 103(1), 191-209(1933)

6. B. Carroll, T. Turpin, B. Adam, C. Alison, T. Ruth, Environmental Impact Assessment Handbook: A Practical Guide for Planners, Developers and Communities(2002)

7. M.M. Rehfisch, G.E. Austin, M.J.S. Armitage, P.W. Atkinson, S.J. Holloway, A.J. Musgrove, M.S. Pollitt, BIOL CONSERV, 112(3), 329-341(2003)

8. P.S. Maitland, A.A. Lyle, AQUAT CONSERV, 1(1), 25-54(1991)

9. M. Kuroki, M.Kawai, B. Jónsson, J. Aoyama, M.J. Miller, D.L.G. Noakes, K. Tsukamoto, ENVIRON BIOL FISH, 83(3), 309-325(2008)

10. T. Hooper, M. Austen, RENEW SUST ENERG REV, 23, 289-298(2013)

11. J.Q. Xia, R.A.Falconer, B.L. Lin, OCEAN MODEL, 32(1-2), 86-104(2010)
12. S. Koohi-Kamali, V.V. Tyagi, N.A.Rahim, N.L. Panwar, H. Mokhlis, RENEW SUST ENERG REV, 25, 135-165(2013)

13. G. Rajgor, RENEW ENERGY, 19-20, 124-128(2017)

14. R.A. Falconer, J.Q. Xia, B.L. Lin, R. Ahmadian, SCI CHINA TECHN, 52, 3413-3424(2009)

15. S. Waters, G. Aggidis, RENEW SUST ENERG REV, 56, 916-921(2016)

16. A. Angeloudis, R.A. Falconer, RENEW ENERGY, 144(A), 337-351(2017) 